\title{
Smoke-free São Paulo: a campaign evaluation and the case for sustained mass media investment
}

\author{
Jorge Alday, MS, (I) Nandita Murukutla, PhD, (') Claudia Cedillo, MBA, (I) Paula Johns, MA, (2) \\ Anna Monteiro, (2) Melanie Wakefield, PhD. ${ }^{(3)}$
}

\author{
Alday J, Murukutla N, Cedillo C, Johns P, \\ Monteiro A, Wakefield M. \\ Smoke-free São Paulo: a campaign \\ evaluation and the case for sustained \\ mass media investment. \\ Salud Publica Mex 2010;52 suppl 2:S216-S225.
}

\begin{abstract}
Although evidence from high-income countries suggests that mass media campaigns can increase knowledge of tobacco harms and encourage smoking cessation, there is little evidence of this from developing countries, particularly related to campaigns that seek to increase support for smoke-free places and laws. Two campaigns that ran in São Paulo, Brazil during implementation of a smoke-free law in São Paulo were evaluated to assess their effectiveness in changing attitudes and creating support for the law. The campaigns were evaluated through street-intercept surveys conducted in early July and late August in São Paulo $(\mathrm{Ns}=603 ; 615)$. Findings reveal that mass communications can generate support for smoke-free laws and underscore the importance of running campaigns that are both well-funded and that use harder-hitting, more graphic messages.
\end{abstract}

Keywords: social marketing; tobacco control campaigns; mass media; communication; evaluation

\author{
Alday J, Murukutla N, Cedillo C, Johns P, \\ Monteiro A, Wakefield M. \\ Sao Paulo libre de humo de tabaco: evaluación \\ de una campaña y el caso para una inversión \\ sostenida en medios masivos. \\ Salud Publica Mex 2010;52 supl 2:S216-S225.
}

\section{Resumen}

Aunque la evidencia de los países de altos ingresos sugiere que las campañas de los medios masivos de comunicación pueden elevar el conocimiento de los daños del tabaco y alentar a dejar de fumar, hay poca evidencia de esto en los países en desarrollo, particularmente en relación con las campañas que tratan de dar más apoyo a los lugares libres de humo de tabaco y a las leyes. Dos campañas que se transmitieron en São Paulo, Brasil durante la ejecución de la ley libre de humo en São Paulo fueron evaluadas para determinar su eficacia en el cambio de actitudes y su contribución al aumento de apoyo a esta la ley. Las campañas fueron evaluadas a través de encuestas realizadas en la calle a principios de julio y finales de agosto en São Paulo (N=603 615). Los hallazgos revelan que la comunicación masiva puede generar apoyo a las leyes antitabaco y subrayan la importancia de la realización de campañas que estén bien financiadas, así como el uso de mensajes gráficos más fuertes.

Palabras clave: mercadeo social; campañas para el control del tabaquismo; comunicación; evaluación; medios de comunicación de masas

(I) World Lung Foundation. New York, NY, USA.

(2) Aliança de Controle do Tabagismo. São Paulo, Brazil.

(3) Cancer Council Victoria. Carlton,Victoria,Australia.

Received on: March 26, 2010 - Accepted on: May 14, 2010

Address reprint requests to: MS Jorge Alday. World Lung Foundation. 6I Broadway, Suite 2800. New York, NY 10006 United States. E-mail: jalday@worldlungfoundation.org 
A strong body of evidence suggests that discrete shortburst mass media campaigns running at high levels of reach and frequency can increase knowledge about the harms of tobacco use and encourage quit attempts. ${ }^{1}$ Sustained use of mass media over longer periods can also contribute to population level decreases in smoking prevalence. ${ }^{1,2}$ Much of this evidence, however, comes from high-income countries. There are few studies that have examined campaigns in developing countries, where investment in tobacco control communications is significantly lower and campaign evaluations are relatively rare.

There is also some published evidence to suggest that tobacco control mass media campaigns, including those about secondhand smoke exposure harms, can be used to support tobacco control policies, such as smoke-free jurisdictions ${ }^{3}$ by changing the social norms associated with tobacco use. ${ }^{4}$ Secondhand smoke messages, however, have not been strongly associated with increased intent to quit. ${ }^{5}$ Of particular interest are results from a recent campaign launched postimplementation of a smoke-free law in Mexico City. ${ }^{6}$ People exposed to the campaign more than doubled their awareness of hazardous chemicals in secondhand smoke. Exposure was also associated with sustained support for the law, while support decreased among those who were not exposed.

There are, however, significant challenges to measuring the impact of a specific campaign on knowledge of secondhand smoke harms and support for smoke-free policies, because these campaigns often coincide and compete with other concurrent campaigns initiated by different actors, with significant press coverage of the policy debate, and with personal experience of the implementation of the law. Conceptually, however, capturing the effects of campaigns that air sequentially can boost the chances of detecting meaningful impacts.

Such an opportunity recently presented itself in São Paulo, Brazil, a state of 40 million people. In Brazil, approximately $20 \%$ of men and $12 \%$ of women currently smoke, ${ }^{7}$ with an upward trend among women. ${ }^{8}$ However, smoke-free policies generally have had populationwide support. Results from a poll in 2008 showed that $88 \%$ of all Brazilians support smoke-free hospitality establishments and $80 \%$ of smokers reported opposition to smoke in indoor places. ${ }^{9}$ Thus, in April 2009, the state legislature passed one of the world's strongest smokefree laws, which came into effect on August 7, 2009. In order to maintain support for the law and counter any opposition, at least two major campaigns aired on television between May and August 2009.

In order to assess the impact of these two different but complementary ads, which aired sequentially, two cross-sectional surveys were conducted: the first in early July 2009 at the end of the government of São Paulo's Drauzio campaign and just prior to the campaign by Aliansa de Controle do Tabagismo-World Lung Foundation (ACT-WLF), thereby capturing the tail effects of the Drauzio campaign and serving as a baseline for the ACT-WLF ad; and the second survey was conducted in late August 2009, after completion of the ACT-WLF ad. This survey also followed the implementation of the law, providing an opportunity to assess the cumulative effects and changes due to these various tobacco control activities.

To our knowledge, this is the first time two contiguous secondhand smoke ads have been evaluated during the implementation of major smoke-free legislation. Since both campaigns aired sequentially in the same region, and since data from comparative (control) locations in which only one or the other campaign aired was unavailable, it was not possible to tease apart the independent and multiplicative effects of the campaigns. Therefore, we expected instead to document the complementary impact of the two contiguous campaigns. Our a priori expectation was that the Drauzio ad would have a greater reach in the population, due to its stronger media weight. We hypothesized that the ACT-WLF ad with its strong, graphic imagery would be particularly effective in changing population knowledge, attitudes and support for the law. Such a finding would be consistent with the evidence that finds that strong, graphic ads with negative imagery tend to achieve more favorable impact, compared to ads that are neutral or positive in tone., ${ }^{1,3}$

\section{Material and Methods}

The evaluation was designed as a collaborative effort among ACT, WLF and research agency Datafolha. Data collection was conducted by Datafolha.

\section{Campaign materials}

The first campaign, developed by the government of São Paulo, featured well-known physician Dr. Drauzio Varella in a restaurant speaking about the forthcoming legislation. In the ad, Dr. Varella noted that similar laws had worked in other countries and that there was significant public support for the measure. The ad was "informational" in nature, providing information about the timeline for establishments to comply or face fines and a direct message to smokers that they should respect the law. The Drauzio ad aired on state television from May 17 to 31 with a related high-circulation merchandising campaign from June 15 to July 14. 
The second campaign was developed to counter opposition from the hospitality industry. Aliança de Controle do Tabagismo (ACT), with technical and financial support from World Lung Foundation (WLF), aired a TV ad called "Quem Não Fuma Não é Obrigado a Fumar" from July 26 to August 16 . The messages in this campaign specifically focused on the health harms of secondhand smoke exposure, presenting workers in the hospitality industry as innocent casualties. The ad was also graphic and hard-hitting: As two smokers smoke in a restaurant, the camera follows toxic secondhand smoke as it is sucked into a waiter's head, which has been altered to look like the head of a vacuum cleaner, down the waiter's throat and into his lungs. The voiceover communicates messages about the number of cigarettes consumed by non-smokers due to secondhand smoke and about how many Brazilians die from secondhand smoke exposure. The ACT-WLF campaign included the television ad, print and billboard materials, a radio ad, and a website.

\section{Sampling method and sample size}

Both surveys were conducted in São Paulo using the in-person street-intercept survey method that has been developed for Datafohla by Universidade de São Paulo (USP). The hallmark of this method is the identification of "flow-points" or data-collection points for research. Over years of research, Datafohla and USP have tracked respondent profiles (age, gender, socioeconomic class, education) interviewed at various flow-points on a master database. "Flow-points" for each study are drawn based on the information available in the database and distributed proportionally to the population to represent all the geographic regions of Sao Paulo City: central, north, south, east and west. Trained interviewers are placed at these flow-points, which include markets, commercial areas, cross streets, randomly select individuals for participation. Quotas for sex and age alone were monitored and applied to create a representative sample of São Paulo. All residents of São Paulo between the ages of 18 and 45 years were considered eligible for participation.

\section{Measures}

The survey instrument was a 20-minute, intervieweradministered, structured questionnaire that was translated from English into Portuguese and ordered so that responses would not be biased by preceding questions. Key indicators of interest were as follows (the order of presentation below does not reflect the question order in the survey but is consistent with the way the data are presented in this paper):
Exposure to campaign messages. Exposure was measured in both surveys through three separate questions. First, unprompted recall was assessed by asking respondents to describe all ads or campaigns about "prevention" and "healthcare" they may have seen in the past 30 days. Second, "category cued recall" was measured by asking respondents to describe all anti-smoking messages seen in the past 30 days. Finally, "ad recognition" was assessed later in the interview by showing respondents images from the campaign and asking them whether or not they recognized them. Ad recognition of the "Drauzio" campaign was assessed at baseline; recognition of the ACT-WLF campaign was assessed in the post-campaign survey.

Appraisal of campaign messages. Appraisal of campaign messages was evaluated through a series of questions in which respondents were asked to indicate on a 5-point Likert scale (ranging from strongly disagree to strongly agree) whether or not they believed the messages in the ad; if they felt the ad provided new information; if it said something personally important; and if it made them pay attention to the ad. All respondents were asked whether the ad made them want to distance themselves from secondhand smoke (SHS) exposure. Smokers were also asked if the ad made them think about their smoking and if it motivated them to quit.

Attitudes towards smoking and knowledge of secondhand smoke (SHS) exposure harms. General attitudes towards smoking were assessed by asking respondents to indicate whether they strongly agreed or disagreed (5-point scale) with statements about smoking and SHS exposure. Consistent with the campaign messages, attitudinal statements that specifically addressed the rights of clients and employees in indoor spaces were included (e.g. employees who work in indoor places have the right to breathe clean air, without cigarette smoke). In order to assess knowledge of SHS exposure harms, respondents were asked to indicate, to the best of their knowledge or belief, whether or not they thought exposure to SHS caused certain diseases, including heart disease, lung disease and mouth cancer. Respondents answered "yes," "no" or "don't know," all of which were considered valid responses.

Awareness of, attitudes towards and support for the law. Attitudes towards the law were assessed through level of agreement with statements about the law and its potential benefits and costs. Support was measured by asking respondents, at both baseline and follow-up, how easy or difficult they thought it would be for others to comply. Respondents were also asked to state their likelihood of reporting violations.

Smoking behaviors. All respondents were asked if they smoke daily, less than daily or not at all. Current smok- 
ers were asked to state their intent to quit in the next 12 months.

\section{Data analysis}

Data were analyzed using SPSS 18.0. Comparisons between proportions were conducted using chi-square tests; mean differences between groups were analyzed using t-tests or ANOVAs. Sub-group comparisons were conducted on smoking status (smokers vs. nonsmokers), gender, age and education. In this paper we describe only differences among groups that were statistically significant at $p<0.05$ level.

Multivariate logistic regressions were conducted to assess the impact of campaign exposure on key attitudes and behaviors, while holding constant potentially confounding variables. The "ad recognition" question was used to define campaign exposure: All those who recognized the campaign in response to the prompted question were coded as the "exposed" group; those who did not recognize the campaign were coded as the "unexposed" group. Impact of exposure to the Drauzio campaign was assessed at baseline; impact of exposure to the ACT-WLF campaign was assessed on the postcampaign data. The analyses were run separately for smokers and non-smokers. In addition to campaign exposure, other covariates entered into the models for smokers included sex, gender, education, TV viewing (for news), and intent to quit. All of these variables, except intent to quit, also formed the covariates in the models for non-smokers. Attitudinal statements were dichotomized for the logistic regressions by combining the top two levels and bottom three levels of the 5-point Likert scales, respectively. For knowledge items, the "false" and "don't know" responses were combined and compared to those who answered "true" to the listed diseases that were said to be caused by SHS exposure.

\section{Results}

\section{Sample characteristics}

The baseline survey was completed by 603 respondents, including 140 smokers (23\%) and 463 non-smokers $(77 \%)$. The post-campaign survey was completed by 618 respondents, including 151 smokers (24\%) and 467 nonsmokers $(76 \%)$. As indicated in Table I, there were no statistically significant differences between the baseline and post-campaign samples.

\section{Campaign recall and recognition}

At baseline, unprompted recall of the Drauzio ad was $10 \%$ and category-cued recall was $24 \%$. In the postcampaign survey, unprompted recall of the ACT-WLF ad was $2 \%$ and category-cued recall was $4 \%$. The higher recall rates of the Drauzio campaign are consistent with

Table I

Respondent ChARACTERISTICS IN THE BASELINE AND the POST-CAMPAIGN SURVEYS. São Paulo, Brazil, July-August 2009

\begin{tabular}{|c|c|c|c|c|c|c|c|}
\hline & \multirow[b]{2}{*}{ Characteristics } & \multicolumn{3}{|c|}{ Baseline (July 2009) } & \multicolumn{3}{|c|}{ Post-campaign (August 2009) } \\
\hline & & $\begin{array}{c}A \\
\text { Total } \\
(n=603)\end{array}$ & $\begin{array}{c}B \\
\text { Smoker } \\
(n=140)\end{array}$ & $\begin{array}{c}C \\
\text { Non-smoker } \\
(n=463)\end{array}$ & $\begin{array}{c}D \\
\text { Total } \\
(n=618)\end{array}$ & $\begin{array}{c}E \\
\text { Smoker } \\
(n=|5|)\end{array}$ & $\begin{array}{c}F \\
\text { Non-smoker } \\
(n=467)\end{array}$ \\
\hline Sex & Women (\%) & 52 & 45 & 54 & 52 & 46 & 54 \\
\hline Age & Mean age & 30 & 30 & 31 & 31 & 32 & 30 \\
\hline \multirow{3}{*}{ Education } & Primary (\%) & 24 & 29 & 23 & 25 & 39 & 21 \\
\hline & Secondary (\%) & 53 & 51 & 53 & 52 & 44 & 55 \\
\hline & Higher (\%) & 23 & 20 & 24 & 23 & 17 & 24 \\
\hline \multirow{3}{*}{ Marital status } & Married / with companion (\%) & 48 & 42 & 50 & 46 & 44 & 47 \\
\hline & Single (\%) & 46 & 51 & 45 & 47 & 46 & 47 \\
\hline & Other (\%) & 5 & 7 & 5 & 7 & 9 & 6 \\
\hline \multirow{4}{*}{ Monthly household income } & Up to $2 x$ min. wage (\%) & 26 & 29 & 26 & 29 & 39 & 26 \\
\hline & More than 2 to $3 \times \mathrm{mw}(\%)$ & 22 & 24 & 21 & 22 & 20 & 23 \\
\hline & More than 3 to $5 \times \mathrm{mw}(\%)$ & 27 & 26 & 28 & 26 & 21 & 28 \\
\hline & More than $5 \times \mathrm{mw}(\%)$ & 21 & 16 & 22 & 19 & 18 & 19 \\
\hline \multirow{3}{*}{ Smoking status } & Daily smokers (\%) & 21 & - & - & 22 & - & - \\
\hline & Less than daily smokers (\%) & 2 & - & - & 2 & - & - \\
\hline & Non-smokers (\%) & 77 & - & - & 76 & - & - \\
\hline
\end{tabular}


its known stronger media weight. Ad recognition followed a similar pattern: $62 \%$ for the Drauzio campaign at baseline, and 35\% for the ACT-WLF campaign in the post-campaign survey. There were no observed differences between smokers and non-smokers in recall or recognition of either campaign. Likewise, there were no differences in recognition of either campaign by participant sex or education. While recognition of the Drauzio campaign did not differ by age, the ACT-WLF ad was most likely to be recognized by 18-24 year olds (ad recognition $=42 \%)$ compared to $25-34$ year olds $(36 \%)$ and 35-45 year old respondents $(29 \%)(p<0.05)$.

Finally, the increased media and news activity on smoking and smoking-related issues was also observed from the baseline to the post-campaign period: $50 \%$ of respondents in the post-campaign survey compared to $17 \%$ at baseline reported coming across smoking-related news stories "every day" in the past 30-day period.

\section{Campaign appraisal}

In order for a campaign to motivate attitudinal and/or behavior change, it is important for the campaign messages to be appraised as believable, personally relevant, and convincing. Table II shows that the two ads were rated equally highly in terms of ease of understanding, believability, grabbing attention, and teaching something new. The ACT-WLF ad was, however, rated higher in terms of personal relevance ( $82 \mathrm{vs.} 73 \%$, respectively; $p<0.05$ ) and being convincing ( 81 vs. $73 \%$, respectively; $p<0.05)$. Among smokers, the ACT-WLF ad was more likely than the Drauzio ad to make smokers want to quit $(80$ vs. $61 \%, p<0.05)$.

\section{Knowledge and attitudinal changes}

Knowledge and attitudinal changes from baseline to the post-campaign period are indicated in Table III. Even at baseline, knowledge about the harms of secondhand smoke (SHS) exposure was high, particularly the risks of lung disease ( $89 \%$ or higher), lung cancer $(78 \%$ or higher) and heart disease (70\% or higher). There was no increase in knowledge from baseline.

Similarly, many attitudes were already polarized at baseline, including disapproval of smoking (more than $85 \%$ ) and discomfort at being exposed to secondhand smoke (more than 90\%). Some attitudes, however, particularly those closely related to the smoke-free law and campaign messages, did change from the baseline to the post-campaign period. Support for smokers' rights to smoke in indoor places diminished significantly $(16 \%$ vs. $9 \%, p<0.05)$. There was increased belief, particularly among non-smokers, that the law would help smokers quit smoking ( $60 \%$ vs. $68 \%, p<0.05)$. Bar and restaurant proprietors, and cigarette manufacturers, were seen as more friendly to the smoke-free law: At baseline, 74\% of respondents perceived bar/restaurant proprietors to be opposed to the law and $80 \%$ perceived cigarette manufacturers to be opposed to the law. Post-campaign, the proportion of respondents who perceived opposition from each party fell to 60 and $74 \%$, respectively. Finally, optimism about compliance increased: $52 \%$ of respon-

Table II

Response to the Drauzio ad at baseline AND the ACT-WLF ad in the post-campaign survey. São Paulo, Brazil, July-August 2009

\begin{tabular}{|c|c|c|c|c|c|c|}
\hline \multirow{4}{*}{$\begin{array}{c}\text { Appraisal } \\
\text { (\% agree or strongly agree) }\end{array}$} & \multicolumn{3}{|c|}{ Drauzio at baseline (July 2009) } & \multicolumn{3}{|c|}{ ACT-WLF ad post-campaign (August 2009) } \\
\hline & $A$ & $B$ & $C$ & $D$ & $E$ & $F$ \\
\hline & Total & Smoker & Non-smoker & Total & Smoker & Non-smoker \\
\hline & $n=130$ & $n=83$ & $n=289$ & $n=459$ & $n=47$ & $n=170$ \\
\hline
\end{tabular}

\begin{tabular}{lllllll} 
Easy to understand & 97 & 95 & 97 & 97 & 100 & 96 \\
\hline Believe what ad says & 92 & 84 & 95 & 95 & 92 & 97 \\
\hline Caught my attention & 88 & 83 & 89 & 91 & 89 & 92 \\
\hline Gave me new information & 80 & 76 & 83 & 80 & 81 & 78 \\
\hline Said something personally important to me & 73 & 78 & 73 & $82^{\mathrm{a}}$ & 81 & $83^{\mathrm{c}}$ \\
\hline More convincing than other ads against smoking & 73 & 72 & 74 & $81^{\mathrm{a}}$ & 81 & $82^{\mathrm{c}}$ \\
\hline $\begin{array}{l}\text { Made me want to change my behavior about being near } \\
\text { people who are smoking }\end{array}$ & 64 & 55 & 66 & 63 & 60 & 64 \\
\hline Made me want to try to stop smoking & - & 61 & - & $80^{\mathrm{b}}$ & 76
\end{tabular}

Superscripts indicate a statistically significant difference $(p<0.05)$.The superscript is placed over the number that is significantly higher in the comparison and the superscript letter refers to the column within which is the number that is significantly lower in the comparison 
Table III

KnOWLedge, ATtitudes AND CONFIDENCE IN SMOKE-FREe POLICIES AT BASELINE and post-campaign. São Paulo, Brazil, July-August 2009

\begin{tabular}{|c|c|c|c|c|c|c|}
\hline \multirow{3}{*}{ Knowledge } & \multicolumn{3}{|c|}{ Baseline (July 2009) } & \multicolumn{3}{|c|}{ Post-campaign (August 2009) } \\
\hline & $A$ & $B$ & $C$ & $D$ & $E$ & $F$ \\
\hline & $\begin{array}{c}\text { Total } \\
(n=603)\end{array}$ & $\begin{array}{l}\text { Smoker } \\
(n=140)\end{array}$ & $\begin{array}{c}\text { Non-smoker } \\
(n=463)\end{array}$ & $\begin{array}{c}\text { Total } \\
(n=6 \mid 8)\end{array}$ & $\begin{array}{l}\text { Smoker } \\
(n=\mid 5 I)\end{array}$ & $\begin{array}{c}\text { Non-smoker } \\
(n=467)\end{array}$ \\
\hline
\end{tabular}

\begin{tabular}{|c|c|c|c|c|c|c|}
\hline \multicolumn{7}{|l|}{ Knowledge of diseases caused by SHS exposure (\% true) } \\
\hline Lung diseases in children & 94 & 93 & 94 & 95 & 89 & 96 \\
\hline Lung cancer in non-smokers & 85 & 81 & 86 & 85 & 78 & 88 \\
\hline Heart disease in non-smokers & 73 & 74 & 73 & 70 & 70 & 70 \\
\hline Mouth cancer in non-smokers & 40 & 40 & 40 & 42 & 37 & 44 \\
\hline \multicolumn{7}{|l|}{ Attitudes towards smoking \& smoke-free policies (\% agree) } \\
\hline People important to you think that no one should smoke & 87 & 84 & 88 & 87 & 86 & 85 \\
\hline Cigarette smoke is dangerous to non-smokers & 98 & 98 & 99 & 98 & 95 & 99 \\
\hline $\begin{array}{l}\text { Employees who work in public spaces have a right } \\
\text { to breathe pure air, free of cigarette smoke }\end{array}$ & 98 & 96 & 98 & 98 & 97 & 98 \\
\hline You become uncomfortable when someone smokes near you & 82 & 53 & 91 & 81 & 54 & 90 \\
\hline $\begin{array}{l}\text { If someone does not want to breathe cigarette smoke, } \\
\text { they should go somewhere else }\end{array}$ & 46 & 51 & 45 & 47 & 46 & 47 \\
\hline Smokers have a right to smoke in indoor public places & $16^{d}$ & $21^{\mathrm{e}}$ & $14^{f}$ & 9 & 16 & 6 \\
\hline $\begin{array}{l}\text { The law that prohibits smoking in enclosed public spaces } \\
\text { will help smokers quit }\end{array}$ & 62 & 58 & 63 & $68^{\mathrm{a}}$ & 59 & $7 I^{c}$ \\
\hline $\begin{array}{l}\text { Bars and restaurants proprietors are against the law } \\
\text { that prohibits smoking in indoor places }\end{array}$ & $74^{d}$ & 73 & $76^{f}$ & 60 & 65 & 60 \\
\hline $\begin{array}{l}\text { Cigarette manufacturers are opposed to the law that prohibits } \\
\text { smoking in enclosed public spaces }\end{array}$ & $80^{\mathrm{d}}$ & 79 & $83^{f}$ & 74 & 75 & 76 \\
\hline $\begin{array}{l}\text { Perceived difficulty in complying with smoking bans } \\
\text { in enclosed public spaces: \% who believe that others } \\
\text { will find it very difficult to comply }\end{array}$ & $52^{d}$ & $53^{e}$ & $52^{f}$ & 41 & 40 & 42 \\
\hline $\begin{array}{l}\text { Willingness to report violations of the smoking } \\
\text { ban (\% totally or very willing to report) }\end{array}$ & 40 & 24 & 45 & 45 & $35^{b}$ & 48 \\
\hline
\end{tabular}

Superscripts indicate a statistically significant difference $(p<0.05)$. The superscript is placed over the number that is significantly higher in the comparison and the superscript letter refers to the column within which is the number that is significantly lower in the comparison

dents at baseline compared to $41 \%$ in the post-campaign period thought that others would find it difficult to comply with the law. Although non-smokers' likelihood to report violations did not increase from baseline to the post-campaign period, interestingly, smokers' selfreported likelihood of reporting violations increased significantly (24\% at baseline vs. $35 \%$ post-campaign said that they would be totally or very willing to report violations, $p<0.05)$.

\section{Influence of campaign exposure}

The results of the multivariate logistic regressions examining the impact of exposure to the campaign on knowledge and key attitudes are displayed in Table IV. As indicated, exposure to the Drauzio campaign at baseline was mostly not associated with any significant changes in knowledge or attitudes. The only exception was that, among non-smokers, those who were exposed to the Drauzio campaign were significantly less likely to agree with the statement that a person who does not wish to breathe cigarette smoke should go to some other place.

Post-campaign, exposure to the ACT-WLF campaign was associated with significant changes in knowledge levels among smokers on two items. Exposed smokers were significantly more likely than unexposed smokers to believe in the risks of heart disease from SHS exposure $(83 \%$ vs. $64 \%, \mathrm{OR}=0.3, p<0.05)$ and to believe in the risks of mouth cancer from SHS exposure (53\% vs. 30\%, OR= $0.4, p<0.05)$. Campaign exposure among smokers was also associated with changes in certain campaign-related 


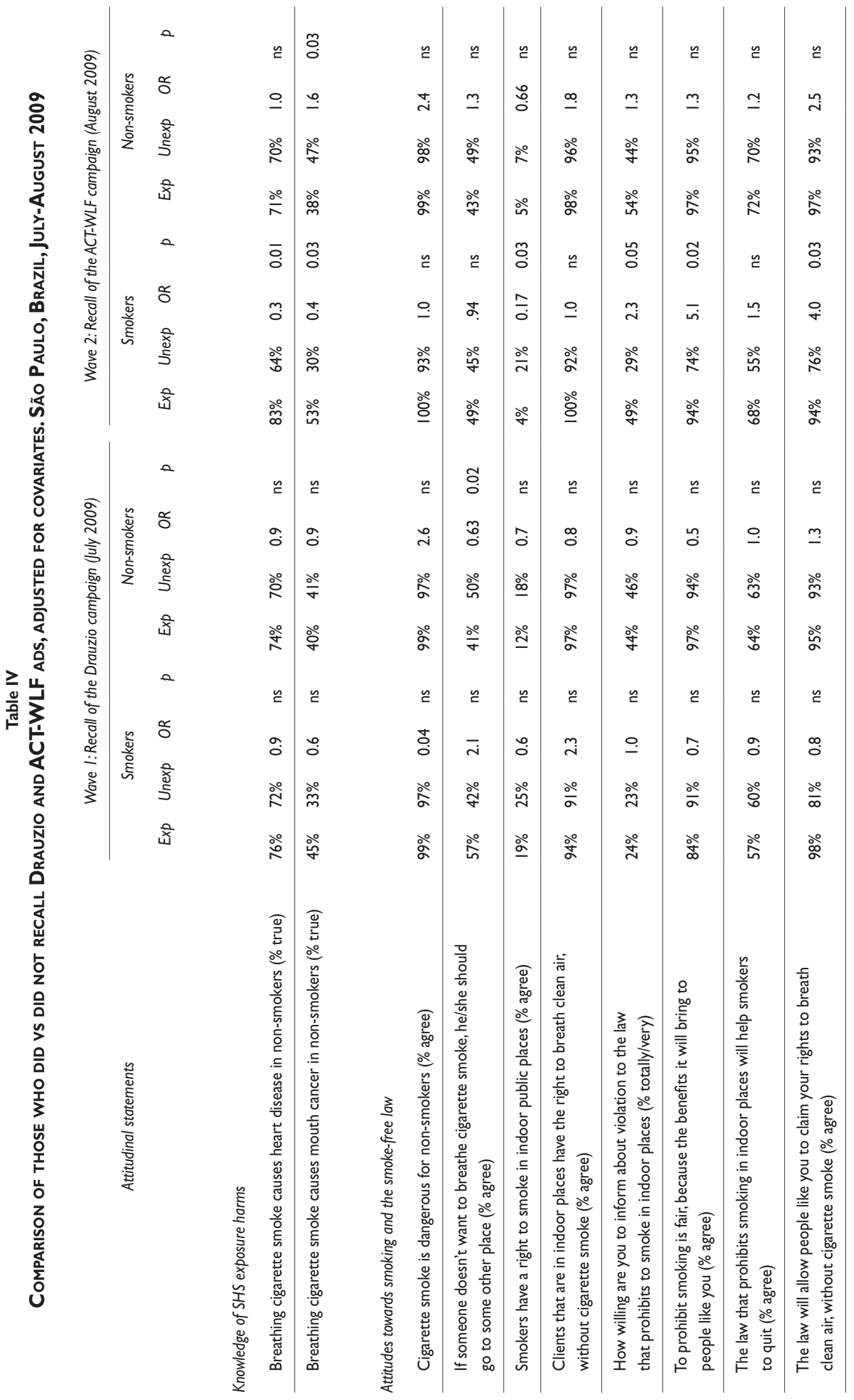


attitudes and beliefs: Smokers who were exposed to the campaign were significantly less likely than unexposed smokers to believe that smokers have a right to smoke in indoor public places ( $4 \%$ vs. $21 \%$, adjusted $\mathrm{OR}=0.17, p=$ $0.03)$; "exposed" smokers were significantly more likely to believe that the smoke-free law was fair and would bring benefits to them $(94 \%$ vs. $74 \%$, adj. $\mathrm{OR}=5.1, p=$ $0.02)$; and they were more likely to believe that the law would allow them to claim their right to breathe clean air without cigarette smoke $(94 \%$ vs. $76 \%$, adj. $\mathrm{OR}=4.0, p=$ $0.03)$. Finally, "exposed" smokers were also significantly more likely to say that they would report violations of the smoke-free law ( $49 \%$ vs. $29 \%$, adj. OR=2.3, $p=0.05$ ). Exposure to the ACT-WLF campaign was not associated with any changes in attitudes or beliefs among non-smokers. Exposure was, however, associated with contrary changes in knowledge levels of one item: Non-smokers who were exposed to the campaign were less likely than unexposed non-smokers to believe that breathing cigarette smoke can cause mouth cancer among those who breathe it (38\% vs. $47 \%$, adj. $\mathrm{OR}=1.6, p=0.03$ ).

\section{Conclusions}

These results provide evidence for the value of welldesigned and well-planned media campaigns in generating and sustaining support for smoke-free initiatives. Our data highlight the importance of strong messaging. Although both campaigns were rated highly on key indicators of effective communication, the ACT-WLF ad was rated as significantly more persuasive, including being more personally relevant and more convincing. Smokers also rated the ACT-WLF ad as significantly more likely to make them want to quit smoking.

The stronger impact of the ACT-WLF ad was also observed in our multivariate regression analyses that isolated the impact of campaign exposure on attitudes and knowledge. Exposure to the Drauzio campaign was mostly unrelated to changes in any attitudes or knowledge, either among smokers or non-smokers. Although exposure to the ACT-WLF ad was not related to attitudinal or knowledge changes among non-smokers (possibly due to a "ceiling effect"), campaign exposure was related to significant changes among smokers, making them significantly more pro-law and improving their knowledge about $\mathrm{SHS}$ exposure harms. In fact, comparing the attitudes of smokers exposed to the ACT-WLF campaign to non-smokers (irrespective of exposure) in the post-campaign period reveals a noteworthy pattern: Exposed smokers' attitudes increased to the level of nonsmokers' views, while unexposed smokers continued to express more negative attitudes to the smoke-free law. Thus, the impact of the campaign appears to have moderated smokers' attitudes and brought them more in line with non-smokers' attitudes and beliefs, which were pro-law and already high. These findings of the differential impact of the Drauzio and ACT-WLF campaigns on population knowledge and attitudes, particularly among smokers, are consistent with the wider body of evidence that has found that more graphic ads tend to be more effective than merely informational ones in motivating behavior and attitudinal change about tobacco. ${ }^{1}$ Moreover, consistent with the findings from our study, the wider evidence indicates that hard-hitting ads are particularly effective in engaging and persuading smokers.

While strong messaging was a merit of the ACTWLF campaign, the Drauzio campaign was clearly effective in its reach. The ad and, therefore, its main messages, was recognized by nearly two-thirds of the population, while the ACT-WLF campaign was recognized by only a little more than a third of the population. The Drauzio campaign, therefore, underscores an important principle in running mass media campaigns: Backing a campaign with significant investments and optimal media weight is critical to ensuring that the greatest number of people are exposed to the campaign. Ultimately, our data suggest that pooling together and marrying the merits of the two campaigns would have yielded the greatest effect: A strong message, as the one used by the ACT-WLF campaign, backed by strong media weight, as with the Drauzio campaign, would have been the most successful at reaching the greatest number of people and at changing population knowledge, attitudes and behaviors.

Before concluding, it is worth noting some of the limitations of our study design. First, our sample cannot be considered truly random because it was created through the street-intercept method, which could be systematically biased by extraneous factors. However, biases in the method were minimized by using a validated method of conducting street-intercept surveys and by ensuring randomness in the selection of respondents. Second, a true baseline survey prior to the launch of the Drauzio campaign and a longitudinal survey design would have further strengthened the evaluation findings. Unfortunately, logistical issues, particularly the unanticipated timing of the Drauzio campaign, precluded this possibility. Fortunately, it was possible to adapt the survey prior to the ACT-WLF campaign to measure the post-campaign impact of the Drauzio campaign and enable comparisons across time-points. Third, our survey may not have provided a fully fair test of the successes of the campaigns in changing knowledge and attitudes. Although we observed population-level 
shifts on some attitudes, particularly those related to the smoke-free law, knowledge and attitude levels on many items were already very high to begin with and left little room for further improvement. Future research would be strengthened by including items with more scope for change. Fourth, our campaign measured recognition of the Drauzio campaign at baseline only and therefore did not allow for a comparison between those exposed to only one campaign and those exposed to both. Ultimately, however, had this data been available, the conclusiveness of such a comparison would have been questionable given that both campaigns aired sequentially in the same region, thereby likely causing trickling or contaminating effects even among populations that were unexposed to the campaigns. Further, it is difficult to attribute changes over time in population attitudes to the advertising campaign(s) versus personal experience of the implementation of the law vs. other media, such as news coverage. Future evaluation studies that utilize a series of comparison groups that each measure the impact of multiple, single and no interventions would be necessary to address this question. Finally, in our analyses that related campaign exposure to attitudinal changes, it is possible that some variables that were associated with both campaign recall and shifting attitudes were not controlled for. These considerations notwithstanding, our regression models were designed to be conservative and include as many potential confounders as could be accommodated, including age, gender, education, intentions to quit (for smokers), and exposure to TV news.

In conclusion, we posit three practical and widerreaching implications of this work. First and most immediately, our evidence finds that mass communications can support legislative goals by generating support for a law, particularly among smokers. The ACT-WLF ad in particular resonated among smokers and is readily available creative material that can be message-tested and adapted with minimal investment for other jurisdictions within Latin America or elsewhere.

Second, our findings are consistent with other assertions in this supplement that recommend a phased approach to mass media communications related to smoke-free implementation. In such an approach, graphic ads about the harms of secondhand smoke may help build support for laws as they are being finalized and maintain support after laws after have come into effect. This model suggests running purely informational ads, such as the Drauzio ad, closer to the implementation date to prepare the public for launch.

Lastly, this research helps build the case for investment in graphic mass media advertising as an efficient method to support smoke-free policy goals. This is particularly important as governments and civil society in low- and middle-income countries continue to seek costeffective communications vehicles to influence tobacco control policy adherence. Reach is critical and should be sought, but relative to unemotional ads, emotionally arousing ads require less investment in broadcasting to achieve the same level of recall. ${ }^{10}$ Ultimately, our findings suggest that broadcasting a strong ad maximizes the likelihood of change.

\section{Acknowledgments}

The authors gratefully acknowledge Bloomberg Philantropies and the Bill \& Melinda Gates Foundation, as part of the Bloomberg Initiative to Reduce Tobacco Use, for their generous support and ongoing commitment to international tobacco control. We would also like to acknowledge the contributions of Instituto Nacional de Cáncer for support of tobacco control in Brazil and partnership in campaign development; Datafohla for consultation on survey design, research fieldwork and original analyses; and World Lung Foundation communications staff, Sandra Mullin, Stephen Hamill and Mego Lien in particular, for strategic support and editing this manuscript.

\section{Declaration of conflicts of interest}

We declare that we have no conflicts of interest.

\section{References}

I. National Cancer Institute. The role of media in promoting tobacco use. Bethesda: US Department of Health and Human Services, National Cancer Institute, 2008.

2. Wakefield MA, Durkin S Spittal M, Siahpush M, Scollo M, Simpson, JA, et al. Impact of tobacco control policies and mass media campaigns on monthly adult smoking prevalence. Am J Public Health 2008;98(8): |443-1450.

3. Kosir M, Gutierrez K. Lessons learned globally from secondhand smoke mass media campaigns. Global Dialogue for Effective Stop Smoking Campaigns. 2010 [Accessed on 2010 january 29]. Available in: http://www. stopsmokingcampaigns.org/secondhand_smoke_campaigns_lessons_ learned_globally.

4. California Department of Health Services. A model for change:The California experience in tobacco control. California Department of Health Services. 1998 [Accessed on 2010 February 2]. Available in: http:// web.archive.org/web/20000925 I70524/http://www.dhs.ca.gov/tobacco/ documents/modelforchange.pdf.

5. Jeff N, Fiore M, Baker TB, Smith SS. Smoking-cessation media campaigns and their effectiveness among socioeconomically advantaged and disadvantaged populations. American Journal of Public Health 2008: 916-324. 
6. Arillo-Santillán E,Thrasher JF, Pérez-Hernández R, Huang L. Social marketing to promote 100\% smoke-free policies: The case of "Porque todos respiramos lo mismo". 2nd SRNT-IAHF Latin America Conference On Tobacco Control. Mexico City: SRNT-IAHF, 2009: I-I5.

7. World Health Organization. WHO report on the global tobacco epidemic, 2009: implementing smoke-free environments. Geneva:WHO press, 2009.

8. Iglesias R, Jha P, Pinto M, Costa e Silva VL, Godinho J.Tobacco control in Brazil. 2007 [Accessed 2010 January 29]. Available in: http://
siteresources.worldbank.org/HEALTHNUTRITIONANDPOPULATION/ Resources/28I627-I095698I40167/ BrazilTobaccoControlFinal.pdf.

9. Aliança de Controle do Tabagismo, Datafohla. Fumo em locais fechados - Brasil. Survey Report. São Paulo:Aliança de Controle do Tabagismo and Datafohla, 2008.

10. Lois B,Wakefield M, Shiner CM, Siegel M. How broadcast volume and emotional content affect youth recall of anti-tobacco advertising. Am J

Prev Med 2008; 35(I): I4-19. 